\title{
Compact CPW-Fed Antenna for Enhanced UWB Applications
}

\author{
Hamed Abdi', Javad Nourinia ${ }^{1}$, and Changiz Ghobadi ${ }^{1}$ \\ ${ }^{1}$ Department of Electrical Engineering, Urmia University, Urmia, Iran \\ Corresponding author: Javad Nourinia (e-mail: j.nourinia@urmia.ac.ir).
}

\begin{abstract}
This paper presents a compact antenna with a co-planar waveguide (CPW) feed line for ultrawideband (UWB) applications. The proposed antenna consists of a beveled radiating patch with a wide rectangular slit at its upper side and a partial ground plane with the insertion of symmetrically two-step beveled tapers at its center and sides, which provides a wide operating bandwidth. The antenna is integrated with narrow rectangular-shaped parasitic elements with different lengths placed adjacent to the radiant patch to significantly enhance the impedance matching and bandwidth, especially at the upper frequencies. The measured results show an $\left|\mathrm{S}_{11}\right|$ less than $-10 \mathrm{~dB}$ bandwidth of $2.5-19.8 \mathrm{GHz}$ with $155 \%$ fractional bandwidth. Simulation results are in good agreement with experimental measurements, which exhibits the validity of the proposed design approach. Moreover, the proposed CPW-fed antenna shows omnidirectional radiation patterns with stable gain within the operational range. The proposed compact antenna with low a profile, lightweight, large frequency bandwidth, ease of fabrication and low-cost material is suitable for UWB applications.
\end{abstract}

INDEX TERMS Coplanar waveguide (CPW), Printed antenna, Ultra-wideband (UWB).

\section{INTRODUCTION}

$\mathbf{U}$ LTRA-wideband (UWB) communications provide a large bandwidth with a high data rate, low transmission power with lengthened battery life and secure communications, and short pulse time modulation with reduced multipath fading [1]. Also, UWB technology has a lot of applications such as high-resolution imaging radars, wireless body area networks (WBANs) and short-range large bandwidth communications [2]. Recently, UWB printed antennas have received much attention because of their attractive advantages such as lightweight, low profile, compact area, low-cost, broadband bandwidth, and easy fabrication [3]. Printed antennas with co-planar waveguide (CPW) feed line are preferred because of its easier integration with surface components, lower radiation loss and less sensitivity to thickness of substrate [4]. Generally, various shapes of radiating elements, such as elliptical, circular, hexagonal, square, and rectangular have been developed to provide wide impedance bandwidth $[5,6]$. To improve the impedance bandwidth of these antennas, different geometries of stubs, slits or slots in the feed line, ground plane, and radiating patch have been introduced significantly enhances the antenna performance [7]. In [8], a CPW-fed antenna with two stacked T-shaped strips inside the square radiating ring is presented which covers the lower band of future $5 \mathrm{G}$ communications $(3.6-6 \mathrm{GHz})$. In [9], by slightly extending the two ground planes and improving the impedance matching a wideband CPW-fed antenna is designed. In [10], the tapered steps technique in the feeding line is presented to UWB behavior and relatively good impedance matching. In [11], using loading parasitic structures a CPW-fed UWB antenna is obtained with the help of the coupling proximity effect. CPW-fed UWB antennas with wideband circular polarization presented in [12] by quadrilateral shaped and in [13] by an asymmetric modified ground plane and a couple of series-aligning inverted Lshaped strip with the ability to as antenna element for designing the linear and planar array antennas.

In this paper, a compact enhanced CPW-fed UWB antenna for applications like microwave imaging, body area networks and short-range high data rate communications is proposed. The wideband operation is obtained by using a slitted radiation patch with a beveled structure and a two-step tapered truncated ground plane with various slopes. To enhance the antenna performance, two pairs of narrow rectangular-shaped parasitic elements with different lengths are embedded at the upper corners of the substrate which excite additional resonances and thus improve the antenna characteristics. The measured $\left|\mathrm{S}_{11}\right|$ shows $17.3 \mathrm{GHz}-10 \mathrm{~dB}$ bandwidth from 2.5 to over $19.8 \mathrm{GHz}$. Besides, the proposed simple CPW-fed UWB antenna exhibits a stably omnidirectional pattern with nearly constant gain over the entire frequency band of interest.

\section{Antenna Design}

Fig. 1 depicts the structure and dimensional parameters of the proposed CPW-fed UWB which to the $y$-axis is symmetrical. The total antenna area is $36 \mathrm{~mm} \times 25 \mathrm{~mm}$ that 
is etched on a low-cost FR4 substrate with a height of 1.6 $\mathrm{mm}, \varepsilon_{\mathrm{r}}=4.4$ and $\tan \delta=0.02$. The proposed antenna is excited with a $50 \Omega \mathrm{CPW}$ feeding line with a width of $\mathrm{W}_{2}=$ $3 \mathrm{~mm}$ and a gap of $0.5 \mathrm{~mm}$. All simulation data are obtained by ANSYS HFSS. In the simulations, conductive surfaces have Perf-E boundary conditions. The radiation boundary is a rectangular cube with a distance of a quarter of the lowest operating frequency free-space wavelength from either side of the antenna except for the backside. The antenna excitation is a rectangular wave-port with dimensions of 6 $\mathrm{mm} \times 4.6 \mathrm{~mm}$ and symmetrical to the signal line. Solution frequency setup is broadband with a maximum delta $S 0.02$. The final values of the antenna parameters are obtained by a parametric study so that each time a parameter changes and the other parameters are fixed. The final dimensions of the presented antenna parameters are listed in TABLE I.

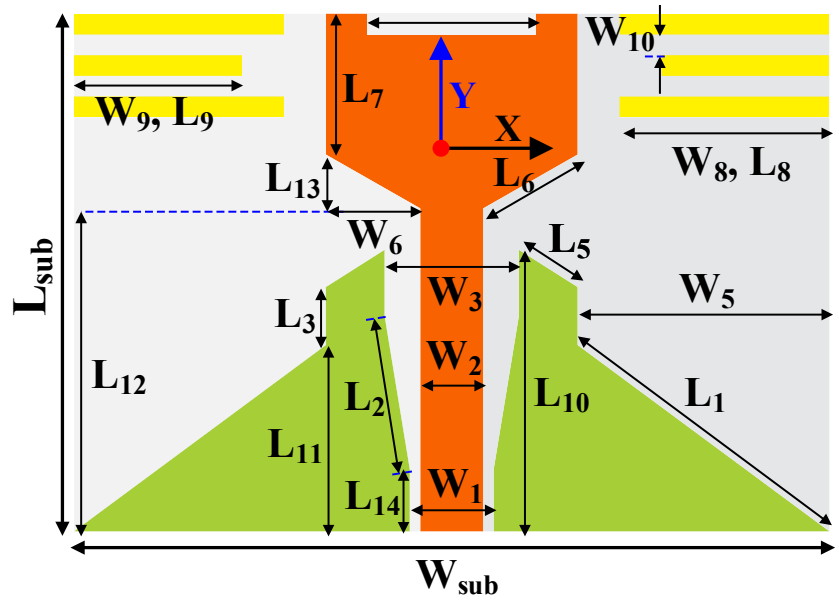

FIGURE 1. The proposed CPW-fed UWB antenna.

TABLE I. Values of Design Parameters

\begin{tabular}{|c|c|c|c|c|c|}
\hline Param. & $\mathrm{mm}$ & Param. & $\mathrm{mm}$ & Param. & $\mathrm{mm}$ \\
\hline $\mathrm{W}_{\text {sub }}$ & 36 & $\mathrm{~W}_{9}$ & 8 & $\mathrm{~L}_{6}$ & 5.2 \\
\hline $\mathrm{W}_{1}$ & 4 & $\mathrm{~W}_{10}$ & 1 & $\mathrm{~L}_{7}$ & 6.8 \\
\hline $\mathrm{W}_{2}$ & 3 & $\mathrm{~L}_{\text {sub }}$ & 25 & $\mathrm{~L}_{9}$ & 1 \\
\hline $\mathrm{W}_{3}$ & 6.4 & $\mathrm{~L}_{1}$ & 15 & $\mathrm{~L}_{10}$ & 13.6 \\
\hline $\mathrm{W}_{4}$ & 8 & $\mathrm{~L}_{2}$ & 7.5 & $\mathrm{~L}_{11}$ & 9 \\
\hline $\mathrm{W}_{5}$ & 12 & $\mathrm{~L}_{3}$ & 2.8 & $\mathrm{~L}_{12}$ & 15.6 \\
\hline $\mathrm{W}_{6}$ & 4.5 & $\mathrm{~L}_{4}$ & 1 & $\mathrm{~L}_{13}$ & 2.6 \\
\hline $\mathrm{W}_{8}$ & 10 & $\mathrm{~L}_{5}$ & 3.4 & $\mathrm{~L}_{14}$ & 3 \\
\hline
\end{tabular}

Fig. 2 illustrates the design process of the proposed antenna ground plane. The basic antenna design (Ant I in Fig. 2(a)) consists of a $50 \Omega$ uniform CPW feed line, a truncated rectangular ground plane and a rectangular radiating patch. In Fig. 3, Ant I has a $-10 \mathrm{~dB}\left|\mathrm{~S}_{11}\right|$ bandwidth for 4.6 to $9.4 \mathrm{GHz}$. Based on the transmission line model for the rectangular radiating patch, the initial width and length of the patch at the dominant mode are calculated using equations (1)-(4) [14]. The width of the patch, $W_{p}$, for a thin substrate is determined by (1)

$$
\mathrm{W}_{\mathrm{p}}=\frac{\lambda_{0}}{2 \sqrt{0.5\left(\varepsilon_{r}+1\right)}}
$$

where $\varepsilon_{\mathrm{r}}$ and $\lambda_{0}$ are the substrate permittivity and free apace wavelength of the resonant frequency. The right choice of $\mathrm{W}_{\mathrm{p}}$ leads to efficient impedance matching and radiation. The patch length $\left(L_{p}\right)$ is calculated using the equation (2)

$$
\mathrm{L}_{\mathrm{p}}=\frac{c_{0}}{2 f_{0} \sqrt{\varepsilon_{\text {eff }}}}-2 \Delta \mathrm{L}_{\mathrm{P}}
$$

where $c_{0}, \varepsilon_{\text {eff, }} \Delta \mathrm{L}_{\mathrm{p}}$ are the free space electromagnetic wave speed, effective dielectric constant and extension of patch length due to the fringing field, respectively. The effective dielectric constant ( $\left.\varepsilon_{\text {eff }}\right)$ is calculated by applying (3)

$$
\varepsilon_{\text {eff }}=\frac{\varepsilon_{r}+1}{2}+\frac{\varepsilon_{r}-1}{2}\left(\frac{1}{\sqrt{1+12 h_{\text {sub }} / \mathrm{W}_{\mathrm{p}}}}\right)
$$

where $h_{\text {sub }}$ is the substrate thickness. Finally, the fringing effect is considered by (4)

$$
\Delta \mathrm{L}_{\mathrm{p}}=0.421 h_{\text {sub }} \frac{\left(\varepsilon_{\text {eff }}+0.300\right)\left(\frac{\mathrm{W}_{\mathrm{p}}}{h_{\text {sub }}}+0.264\right)}{\left(\varepsilon_{\text {eff }}-0.258\right)\left(\frac{\mathrm{W}_{\mathrm{p}}}{h_{\text {sub }}}+0.813\right)}
$$

with placement $\varepsilon_{\mathrm{r}}=4.4, \mathrm{~h}_{\text {sub }}=1.6 \mathrm{~mm}$ and $f_{0}=7 \mathrm{GHz}$, the center frequency of UWB range (3.1-10.6 GHz), in equations (1)-(4), the initial dimensions of the rectangular patch are $\mathrm{W}_{\mathrm{p}}$ $=13.03 \mathrm{~mm}$ and $\mathrm{L}_{\mathrm{p}}=9.58 \mathrm{~mm}$. Alternatively, the width and length of the patch are adjusted to be $\mathrm{W}_{\mathrm{p}}=12 \mathrm{~mm}$ and $\mathrm{L}_{\mathrm{p}}=$ $9.4 \mathrm{~mm}$, based on full-wave optimization. Also, the size of the antenna substrate is directly proportional to the wavelength at the lower edge of the working band.

By inserting a two-step beveled taper at the sides of the partial ground plane (Ant II in Fig. 2(b)), the bandwidth is broadened and it is enhanced from 6.2 to $12 \mathrm{GHz}$. Finally, by forming another two-step beveled taper with different slope beside the feed line (Ant III in Fig. 2(c)), impedance matching extending from 2.4 to $10 \mathrm{GHz}$. This is because the two-step beveled taper ground planes increase the electrical length, act as a matching transformer and lead to a capacitive loading which negates the inductive reactance of the radiating patch to approach an approximately real resistive input impedance. The two-step beveled tapers in the ground plane improve the impedance matching and effect on the lower edge frequency. Therefore, by properly adjusting the slopes of the beveled tapers at the center and sides of the 
ground plane, a compact CPW-fed antenna is obtained, covers a wide bandwidth.

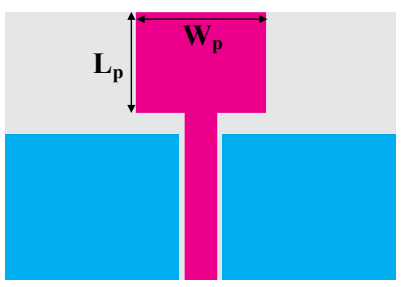

(a)

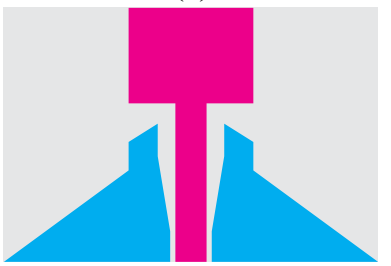

(c)

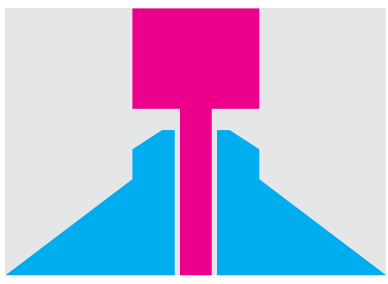

(b)
FIGURE 2. Ground plane design process: (a) truncated ground (Ant I), (b) two-step bevel taper ground (Ant II) and (c) proposed ground (Ant III).

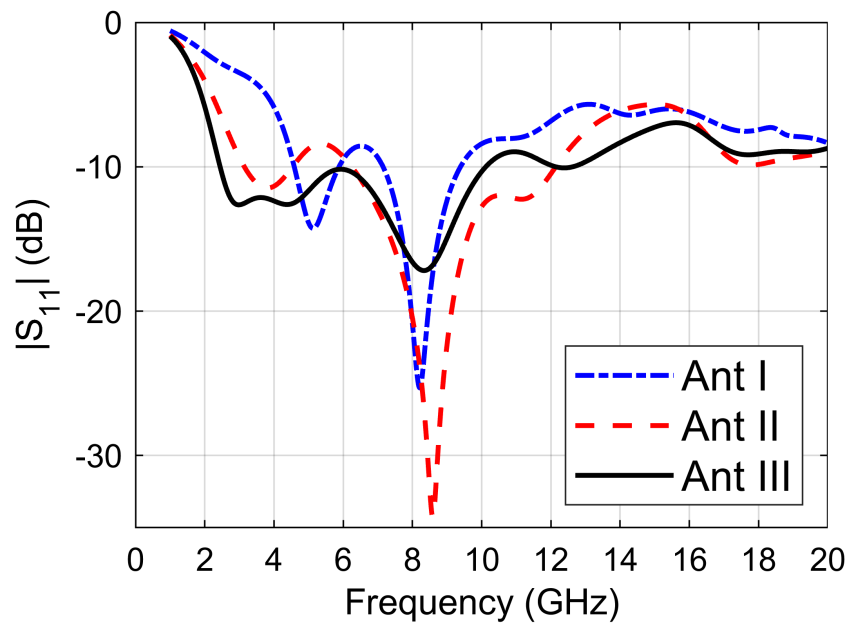

FIGURE 3. Simulated $I S_{11} \mid$ of ground plane design process for antennas shown in Fig. 2.

Fig. 4 shows the design procedure of the proposed antenna radiating patch. Ant III is the basic radiating patch with a -10 $\mathrm{dB}$ bandwidth from 2.4 to $10 \mathrm{GHz}$. Fig. 5 shows that adding bevels to the rectangular patch (Ant IV in Fig. 4(b)) improves the impedance matching. Finally, by adding a wide rectangular slit at the upper edge of the radiating patch (Ant $\mathrm{V}$ in Fig. 4(c)), impedance matching broadens from 2.5 to 12.8 GHz. This is because the bevels and slit at the radiating patch perturb the current distribution, smooth changing from one resonance to another, create additional surface paths and excite more resonances. Therefore, wider impedance matching is obtained, especially at the upper frequency edge. Base on simulation data, it is observed that the lower and upper frequency edges are easily controlled by forming the ground plane and radiating patch, respectively. So, by correctly tuning their dimensions, the impedance matching and frequency band edges significantly improve.

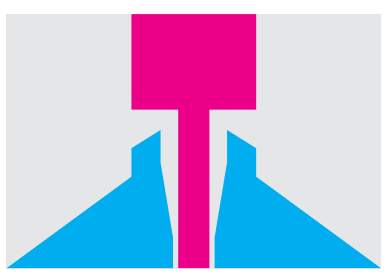

(a)

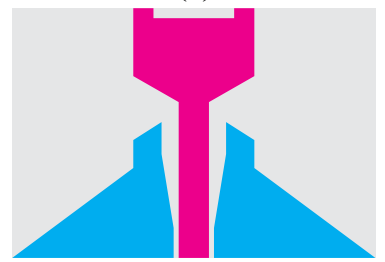

(c)

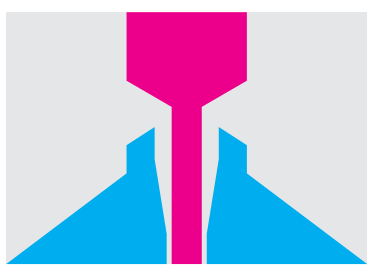

(b)
FIGURE 4. Radiating patch design procedure: (a) square patch (Ant III), (b) bevelled patch (Ant IV), and (c) proposed patch (Ant V).

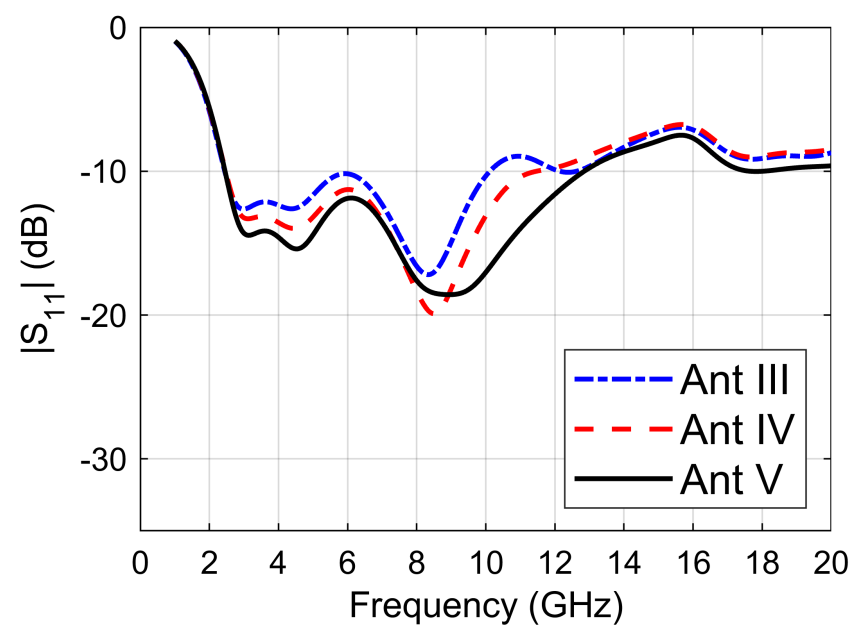

FIGURE 5. Simulated $\left|S_{11}\right|$ of radiating patch design procedure for antennas shown in Fig. 4.

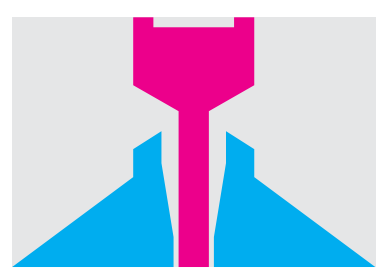

(a)

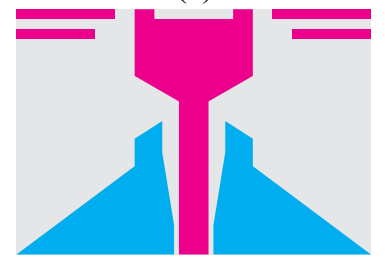

(c)

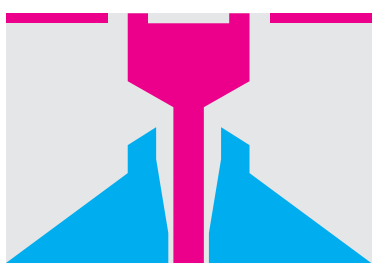

(b)

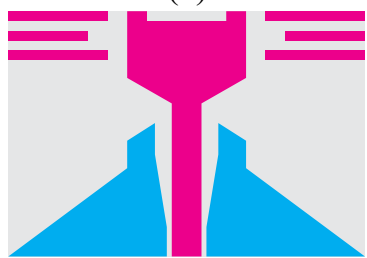

(d)
FIGURE 6. Parasitic elements design steps: (a) Ant V, (b) Ant VI, (c) Ant VII, and (d) proposed antenna (Ant VIII). 
Fig. 6 shows the design steps of the proposed antenna parasitic elements. As observed in Fig. 7, adding two pairs of triple narrow rectangular-shaped parasitic elements with different lengths embedded at the upper corners of the substrate near to the radiating patch improves the impedance matching and bandwidth, especially at the upper frequencies. This is because the parasitic strips in co-planar form act as directors and based on the proximity effect of electromagnetic coupling more effective resonates are excited. Therefore, matching performance is improved at lower and upper frequency bands. The distance between parasitic elements with the radiating patch, spacing and dimensions of them need to be carefully adjusted to obtain high performance.

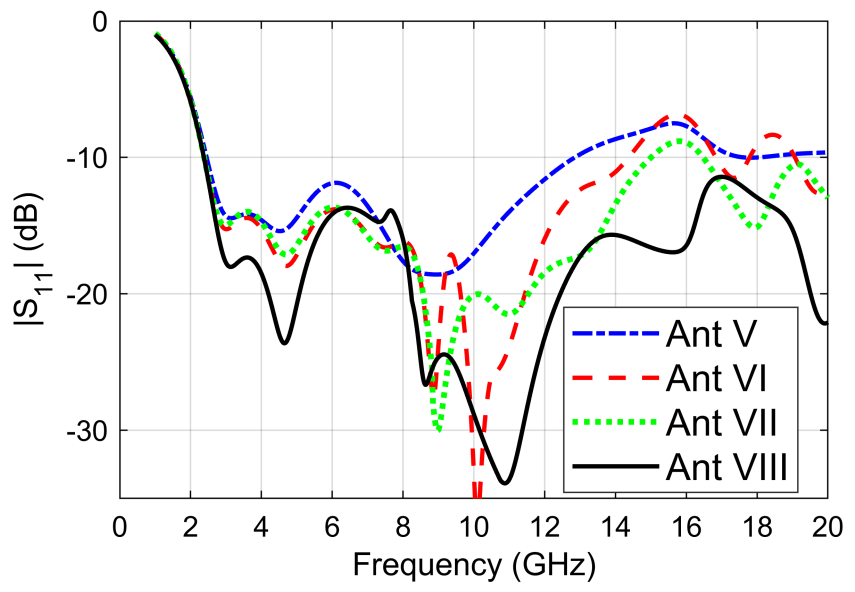

FIGURE 7. Simulated $I S_{11} \mid$ of parasitic elements design steps for antennas shown in Fig. 6.

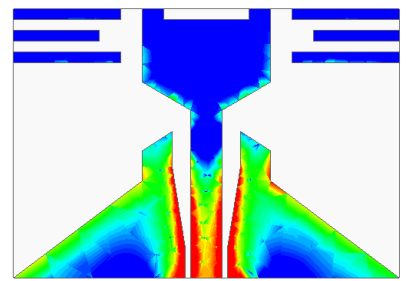

(a)

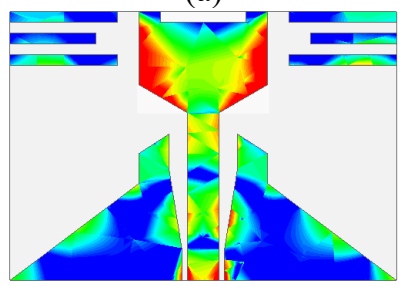

(c)

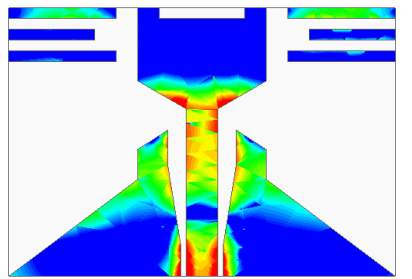

(b)

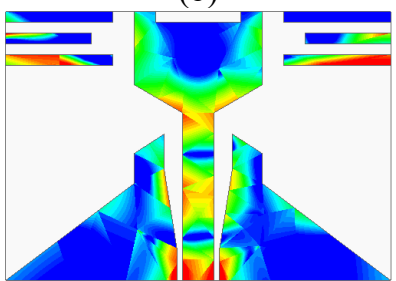

(d)
Min.

FIGURE 8. Simulated current distributions of the proposed CPW-fed UWB antenna at: (a) $4 \mathrm{GHz}$, (b) $8 \mathrm{GHz}$, (c) $12 \mathrm{GHz}$, and (d) $16 \mathrm{GHz}$.

Fig. 8 shows the simulated current distributions of the proposed antenna at 4, 8, 12, and $16 \mathrm{GHz}$. In Fig. 8(a) at 4 $\mathrm{GHz}$, the surface current is intensified on the inner edges of the ground plane. This distribution indicates that forming the interior edge of the ground plane affects the lower frequency band. With the frequency increasing at $8 \mathrm{GHz}$ in Fig. 8(b), the currents are concentrated along the beveled taper of the patch, and hence the antenna matching changes at this band due to the beveled patch resonances. Fig. 8(c) shows the current surface is stronger on the sides of the radiating patch at $12 \mathrm{GHz}$. In Fig. 8(d) at $16 \mathrm{GHz}$, the maximum surface current magnitude is conducting along with the parasitic element. It is concluded the embedding of parasitic elements extends the upper frequency band.

\section{Experimental Results}

Fig. 9 shows the fabricated prototype antenna. Fig. 10 presents the simulated and measured $\left|S_{11}\right|$ of the proposed $\mathrm{CPW}$-fed antenna. $\left|\mathrm{S}_{11}\right|$ is measured using a PNA model of E8363C. The measured results show $-10 \mathrm{~dB}\left|\mathrm{~S}_{11}\right|$ bandwidth extends from 2.5 up to $19.8 \mathrm{GHz}$ with $155 \%$ fractional bandwidth (FBW). There exists a difference between measured and simulated results due to the effects of SMA soldering, PCB machining accuracy, substrate quality, broadband simulation, free space measurement and the feeding cable. However, there is a shift in the frequency measured response, especially at the upper frequencies. It is recommended in the UWB antenna to use high-quality substrates with low permittivity and low loss tangent.
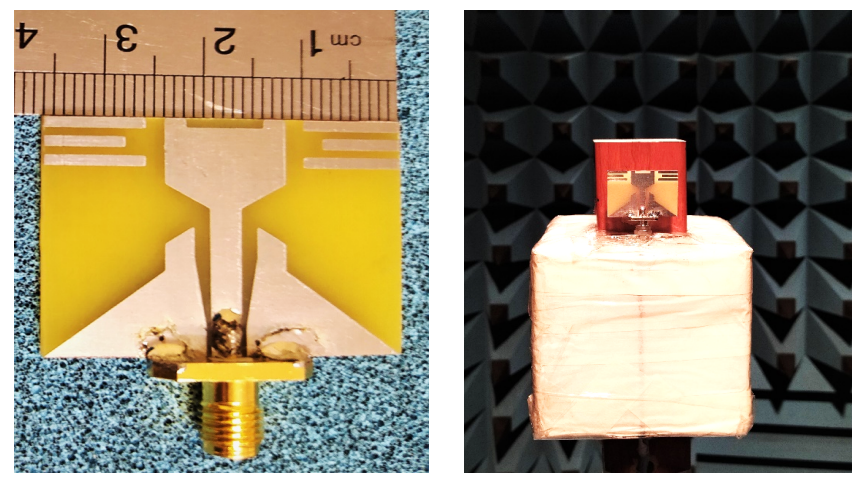

FIGURE 9. Fabricated prototype antenna with attached SMA.

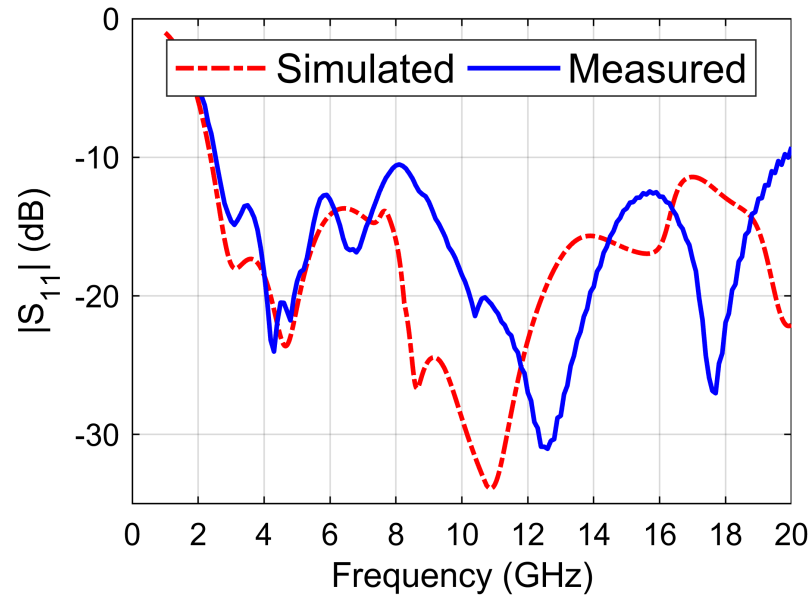

FIGURE 10. Simulated and measured $\left|S_{11}\right|$ of the proposed CPW-fed antenna. 

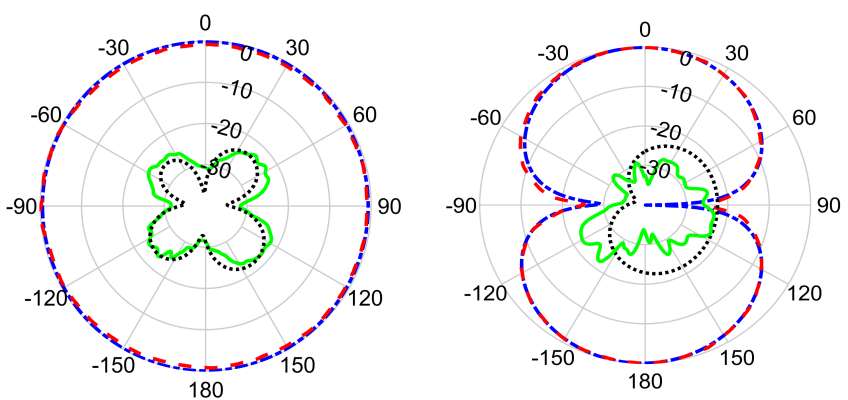

(a)
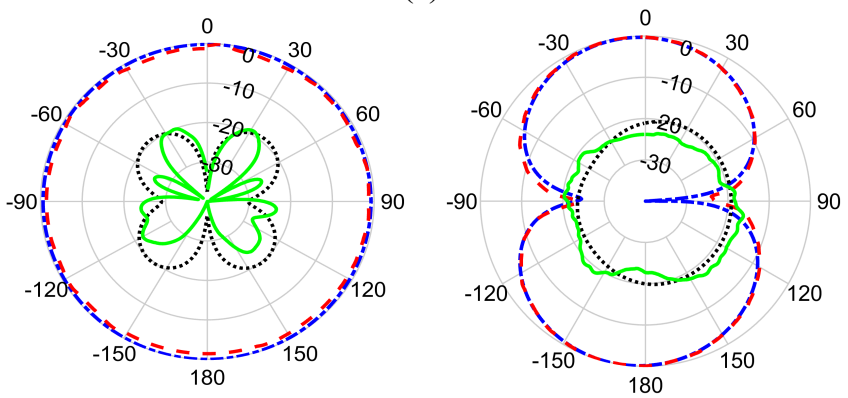

(b)
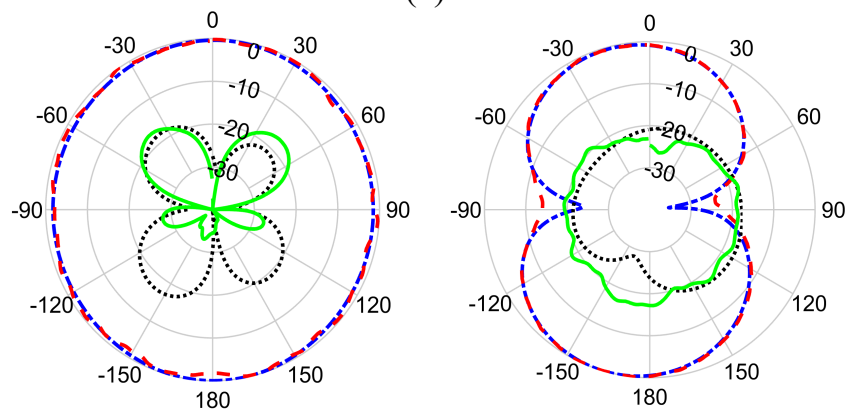

(c)

Simu. Co-Pol.

Simu. Cross-Pol.

- - - Meas. Co-Pol. Meas. Cross-Pol.

FIGURE 11. Simulated and measured normalized radiation patterns in $x z$ (left) and yz (right) planes at: (a) $4 \mathrm{GHz}$, (b) $8 \mathrm{GHz}$, (c) $12 \mathrm{GHz}$.

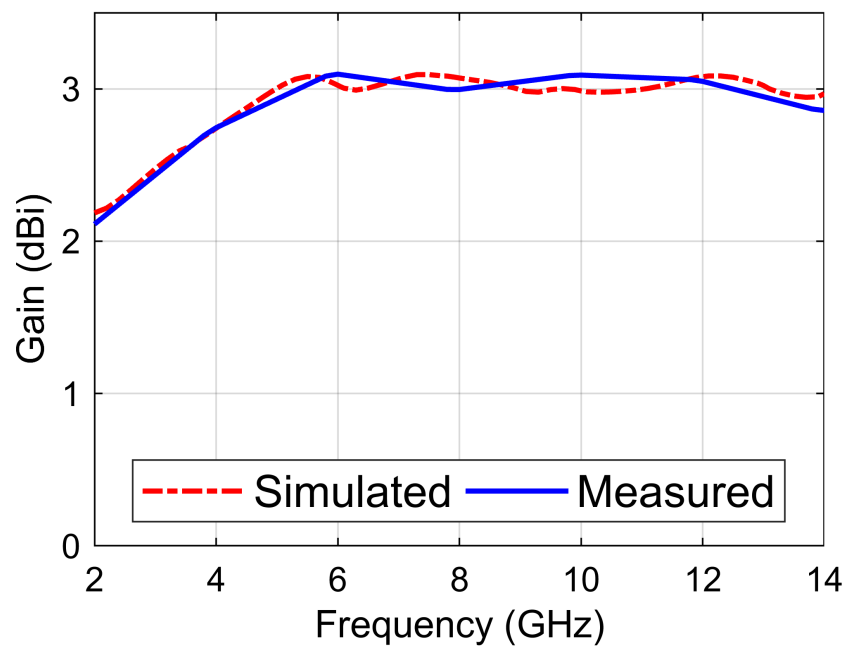

FIGURE 12. Simulated and measured peak gains of the proposed UWB antenna.

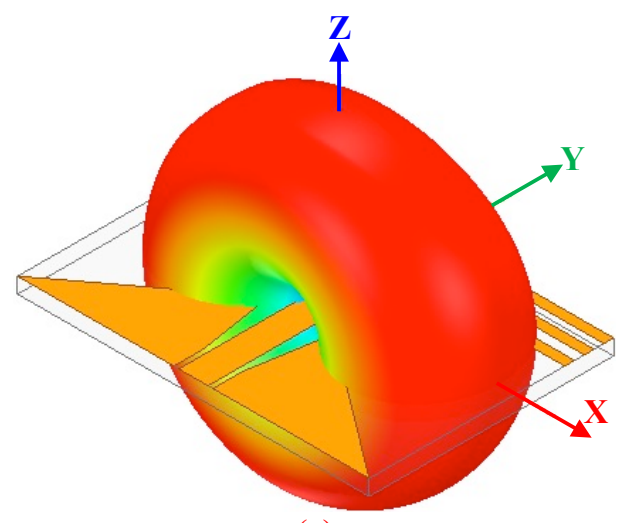

(a)

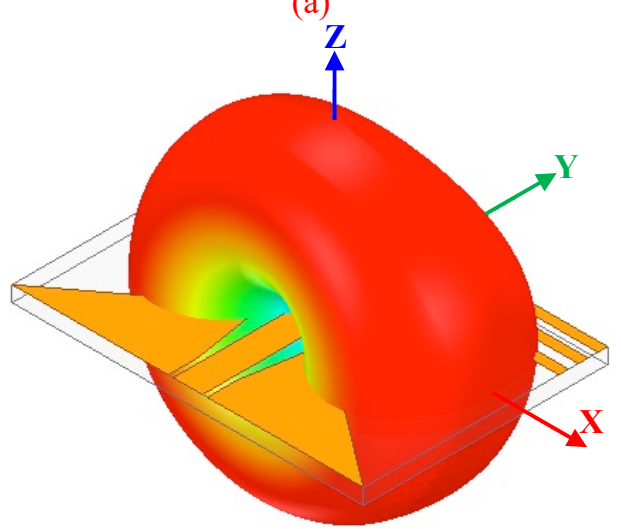

(b)

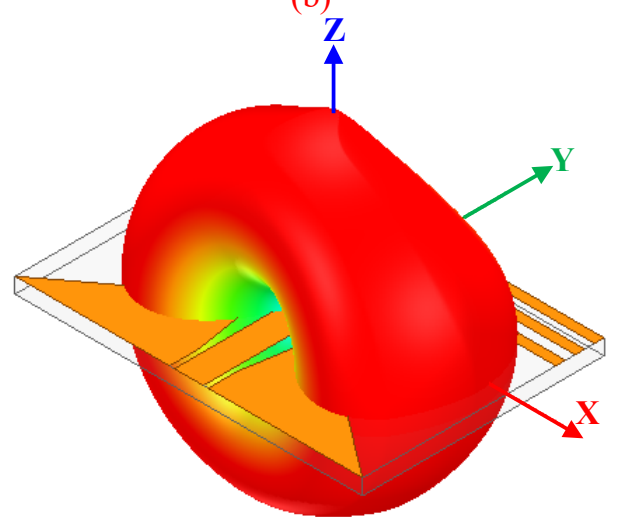

(c)

Min

Max.

FIGURE 13. Simulated normalized 3D radiation patterns at: (a) $4 \mathrm{GHz}$, (b) 8 $\mathrm{GHz}$, (c) $12 \mathrm{GHz}$.

TABLE II. A Comparison with Other CPW-Fed UWB Antennas

\begin{tabular}{|c|c|c|c|}
\hline Ref. & Bandwidth $(\mathrm{GHz})$ & Bandwidth $(\mathrm{GHz})$ & Size $(\mathrm{mm} \times \mathrm{mm})$ \\
\hline$[11]$ & $2.2-14$ & 11.8 & $26 \times 27$ \\
\hline$[15]$ & $2-9.5$ & 7.5 & $47 \times 47$ \\
\hline$[16]$ & $1.9-12$ & 10.1 & $48 \times 55$ \\
\hline$[17]$ & $2.4-14$ & 11.6 & $38.3 \times 34.5$ \\
\hline$[18]$ & $2.8-18$ & 15.2 & $50 \times 38$ \\
\hline This Work & $2.5-19.8$ & 16.6 & $36 \times 25$ \\
\hline
\end{tabular}

Fig. 11 shows the simulated and measured radiation patterns in the planes of xz (E-plane) and yz (H-plane) at 4, 8, and $12 \mathrm{GHz}$. The results exhibit a stably omnidirectional 
pattern and low-level cross-polarization even at upper frequency. This is due to the purity of the horizontal electrical current alignment and elimination of the vertical electrical currents in the parasitic elements which result in the antenna cross-polarization enhancement. Fig. 12 shows the simulated and measured peak gains of the proposed UWB antenna. A nearly constant gain is observed within the bandwidth. Gain measured is obtained by the comparison method in a pyramidal chamber with ETS 3117 dual-ridged horn as reference and transmitter antennas. Fig. 13 illustrates the $3 \mathrm{D}$ radiation patterns of the proposed antenna to a better description of the antenna radiation behavior. Finally, a comparison with other CPW-fed UWB antennas is listed in Table II. It can be seen that the proposed antenna has a compact size and enhanced bandwidth.

\section{CONCLUSION}

A simple CPW-fed antenna with the advantages of UWB bandwidth, compact size, low fabrication cost and stable omnidirectional radiation pattern even at upper frequencies was presented. The use of a two-step beveled tapered partial ground plane with different slopes and a beveled radiation patch with a wide rectangular slit at its upper side was broadened impedance bandwidth. A wider impedance matching was obtained by embedding two pairs of narrow rectangular-shaped parasitic elements with different lengths beside the radiation patch at the substrate corners. The measured $\left|\mathrm{S}_{11}\right|$ shows that the $-10 \mathrm{~dB}$ impedance bandwidth spreads from $2.5-19.8 \mathrm{GHz}(17.3 \mathrm{GHz}, 155 \%)$ with good agreement against simulation result which validates the antenna UWB performance. Finally, the proposed CPW-fed UWB antenna is a good choice for UWB applications like medical imaging and indoor wideband communications.

\section{REFERENCES}

[1] M. Elhabchi, M. N. Srifi, and R. Touahni, "A wideband filteringantenna inspired with symmetric T-shaped slots and rotated L-shaped strips for C and X-band eliminations," Advanced Electromagnetics, vol. 9, no. 1, pp. 1-6, March 2020.

[2] B. Heydarpanag, Ch. Ghobadi, J. Nourinia, P. Beigi, and M Majidzadeh, "Size miniaturized coaxial probe fed antenna for multiband applications," Advanced Electromagnetics, vol. 9, no. 1, pp. 1-5, May 2020.

[3] A. Pandey, Practical microstrip and printed antenna design, $1^{\text {st }}$ ed., Artech House, Norwood (Canada), p. 443, 2019.

[4] T. C. Edward and M. B. Steer, Foundations for microstrip circuit design, $4^{\text {st }}$ ed., John Wiley \& Sons, Chichester (United Kingdom), p. 659, 2016.

[5] R. Cicchetti, E. Miozzi, and Or. Testa, "Wideband and UWB antennas for wireless applications: A comprehensive review," International Journal of Antennas and Propagation, Article ID 2390808, 45 pages, 2017.

[6] A. Esmaeilkhah, Ch. Ghobadi, J. Nourinia and M. Majidzadeh, "On effect of planar scaling on microstrip patch antenna performance," Advanced Electromagnetics, vol. 8, no. 1, pp. 1-7, March 2019.

[7] I. Amdaouch, O. Aghzout, A. Naghar, and A. V. Alejos, F. Falcone, "Design of UWB compact slotted monopole antenna for breast cancer detection," Advanced Electromagnetics, vol. 8, no. 5, pp. 1-6, December 2019.

[8] M. Karthikeyan and R. Sitharthan, T. Ali, and B. Roy, "Compact multiband CPW fed monopole antenna with square ring and T-shaped strips," Micro. Opt. Technol. Lett., vol. 62, pp. 926-932, 2020.

[9] D. Mandal and S. S. Pattnaik, "Wide CPW-fed multiband wearable monopole antenna with extended grounds for GSM/WLAN/WiMAX applications," Int. J. Antenn. Propag. vol. 19, p. 4264513, 2019.

[10]T. Saeidi, I. Ismail, W. P. Wen, and A. R. H. Alhawari, and A. Mohammadi, "Ultra-Wideband antennas for wireless communication applications," Int. J. Antenn. Propag., vol. 19, p. 7918765, 2019.

[11]R. K. Garg, M. Vikraman, D. Nair, S. Singhal, and R. Tomar, “A new type of compact ultrawideband planar fractal antenna with WLAN band rejection," Micro. Opt. Technol. Lett., vol. 62, pp. 856-875, 2020.

[12]P. Chaudhary, A. Kumar, "Compact ultra-wideband circularly polarized CPW-fed monopole antenna," Int. J. Electron. Commun., vol. 107, pp. 137-145, 2019

[13] H. Alsariera, Z. Zakaria, and A. B. A. M. Isa, "New broadband Lshaped CPW-fed circularly polarized monopole antenna with asymmetric modified ground plane and a couple series-aligning inverted L-shaped strip," Int. J. Electron. Commun., vol. 118, p. 153139, 2019.

[14] C. A. Balanis, Antenna theory analysis and design, John Wiley \& Sons, Inc., Fourth edition 2016.

[15]P. Khanna, A. Sharma, A. K. Singh, and A. Kumar, "A CPW-fed octagonal ring shaped ultra wide band antenna for wireless applications," Advanced Electromagnetics, vol. 7, no. 3, pp. 87-92, August 2018.

[16]Z. A. A. Hassain, A. R. Azeez, M. M. Ali, and T. A. Elwi "A modified compact bi-directional UWB tapered slot antenna with double band notch characteristics," Advanced Electromagnetics, vol. 8, no. 4, pp. 74-79, September 2019

[17] S. Kundu, S. K. Jana, "A leaf-shaped CPW-fed UWB antenna for GPR applications," Micro. Opt. Technol. Lett., vol. 60, no. 4, pp. 941-945, 2018.

[18]A. Upadhyay, R. Khanna, "A CPW-fed tomb shaped antenna for UWB applications," International Journal of Innovative Technology and Exploring Engineering (IJITEE), vol. 8, pp. 67-72, July 2019. 